\section{How context influences language processing and comprehension}

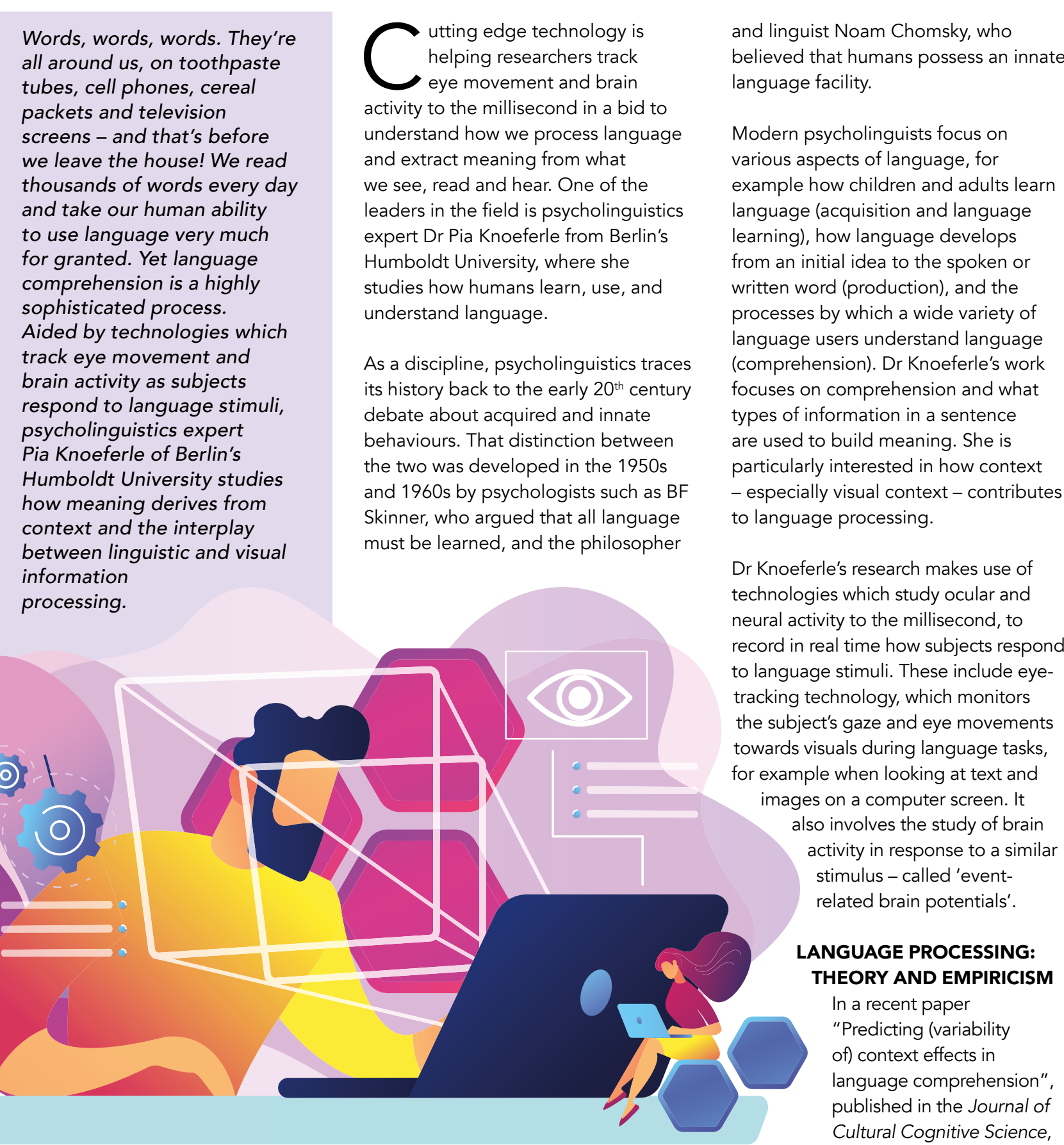

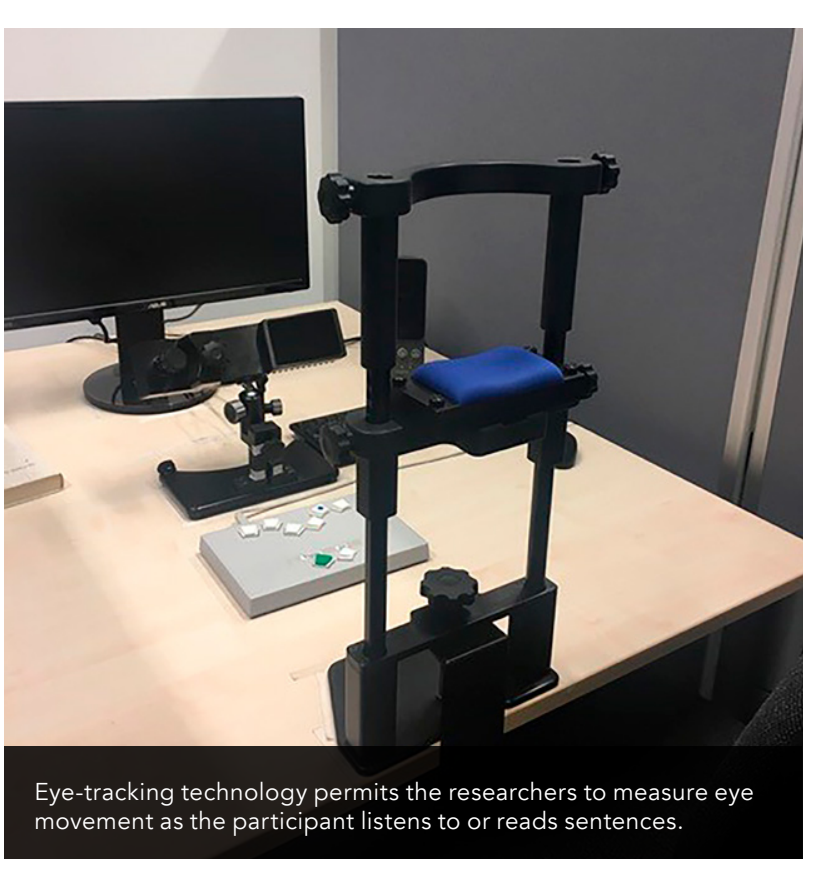

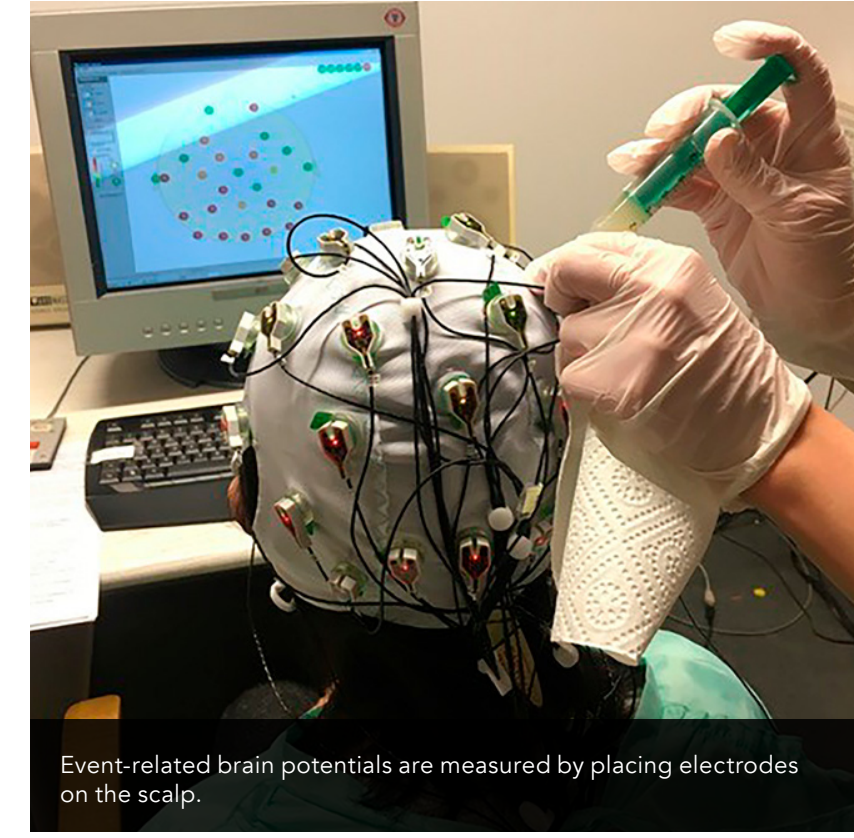

Dr Knoeferle presents an in-depth review of language processing theory. She prediction in language comprehension that is, how we can begin to understand and predict meaning before we actually encounter a specific word.

Work in this area of psycholinguistics has developed over the past 40 years. Initially, researchers looked at how syntax - language structure - might enable individuals "to recover an interpretation from language input in real time". They concluded that comprehension should be viewed as a two-stage process. In this way, the order of key words, for example a subject, verb and object, intially hips sugest

The development of technologies has further enabled the study of brain activity while people perform various tasks. Among the most notable findings for linquistics has been the discovery of event-related brain potentials brain responses to words and other stimuli. Measured to around $400 / 600$ miliseconds post stimulus - the $\mathrm{N} 400$ P600 effect' - brain potentials show how quickly the brain reacts to expectations of a word and semantic associations (N400) as well as to structure-related processes (P600)

LANGUAGE IN CONTEXT Dr Knoeferle looks at what the research iterature says about context-focused approaches to comprehension. Studies have looked at verification and the looking for example asking subjects to verify a sentence in the context of a 'semantic priming', in which brain responses to a second stimulus are found to be faster when that second stimulus is related to a first one (such as the word 'cat' following 'dog') than (e.g., he word 'disc' following 'dog',

Our immediate environment can affect language comprehension in real time.

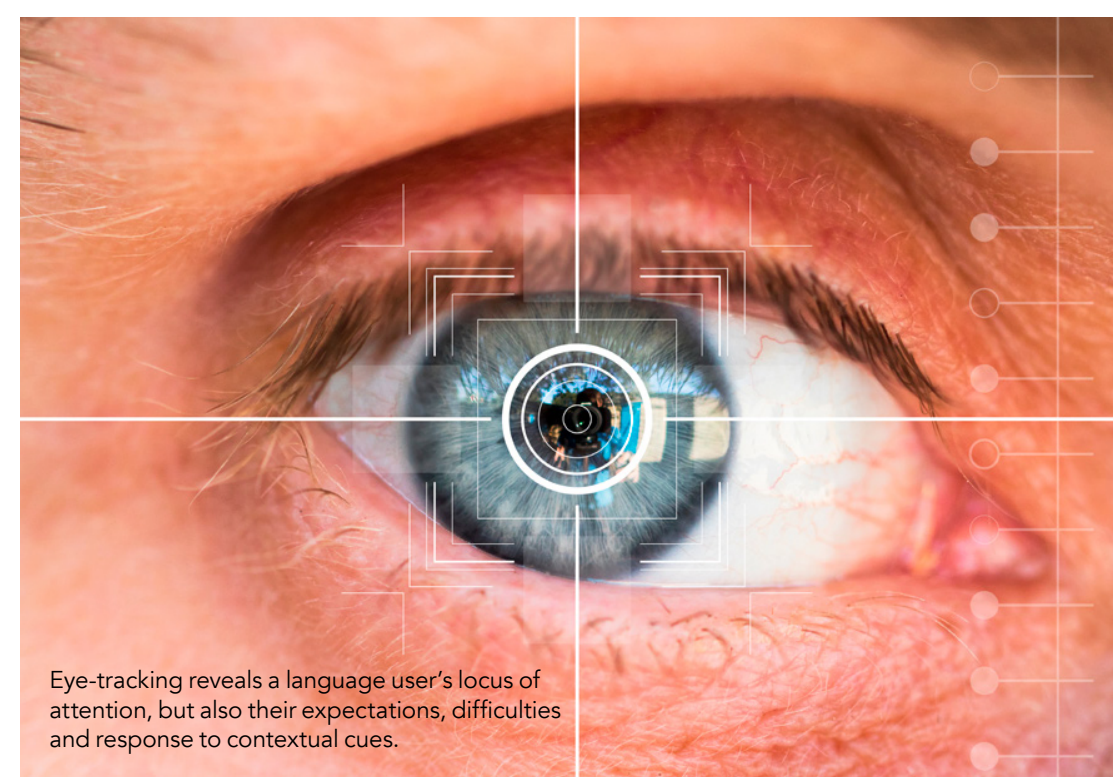
picture. Research has also considered 


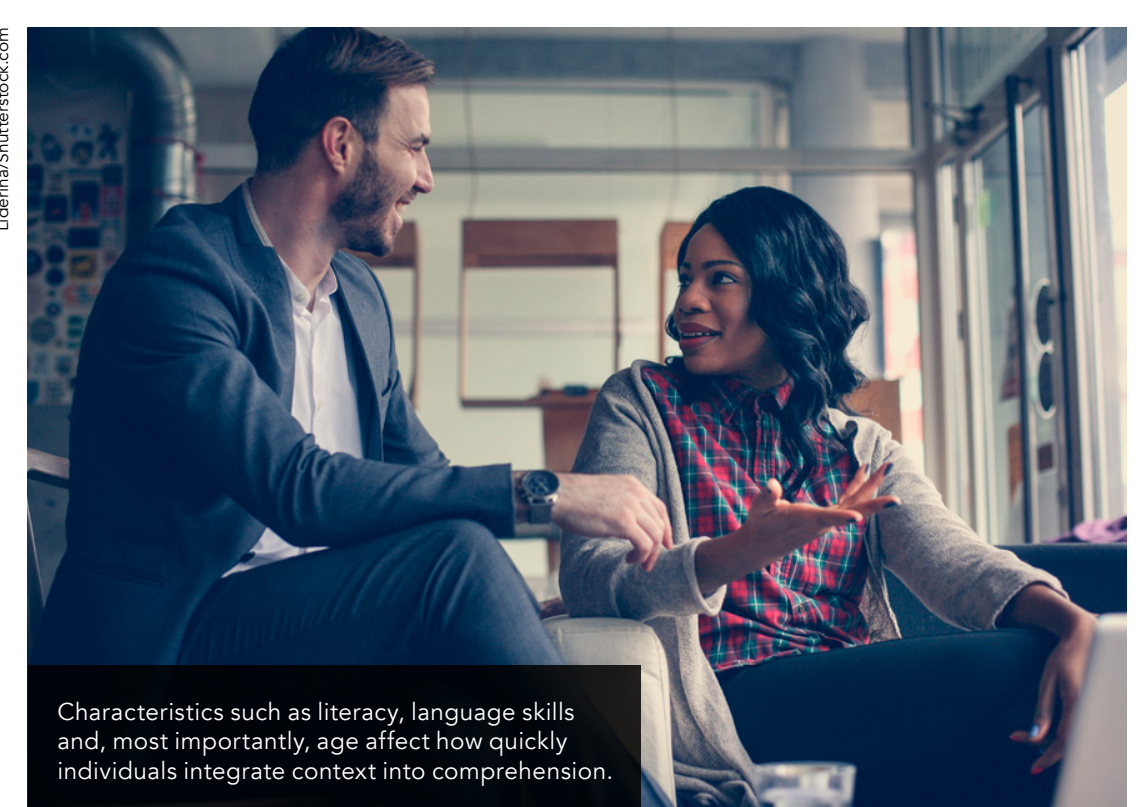

Context is important in language comprehension, but context effects are variable, and some are more robust than others.

associated mechanisms in language comprehension. Her paper discusses these processes at length in light of extant academic research. The first is building structure and assigning an interpretation". This includes forming meaning which is "informed by guistic and world knowledge, and the

The second is "grounding the erpretation in a model of the world/ (interna/ content or concept and associated personal experience. Finally, the third nterpretation against representations of the world/ non-linguistic visual context and revising as necessary and understanding by linking it to personal experience.

Dr Knoeferle argues that research approaches to date suggest that more Writes: "Empirical research has provided more and more evidence that we must "mental representation" of senten process is "verifying the structure and differtion should be paid to the poten differences between individuals. She
The research literature suggests that a visually depicted action affects adults than it does with kindergarten hildren, or with adults aged over 60 .

Regarding how words relate to the situation and environment in which they arise, Dr Knoeferle finds there is a relatively direct and strong connection between action words and images, for example between seeing an image of someone painting and understanding the word 'paint'. However, seeing someone smile is far more ambiguous and could relate to a range of things or words. They may be happy or amused be looking forward to something, or be trying to cheer someone up, and or words could be happy," amused",

As a result, Dr Knoeferle argues that As a rest, Dr Koefere argues that that relates to things and events: "Referential cueing of information in visual context elicits - on average and by comparison - more rapid and stronger effects than non-referential mediation of visual context."

representations) for developing theories of real time language comprehension ations of the listener and his characteristics such as age, or

\section{PREDICTING CONTEXT EFFECTS}

Dr Knoeferle's research review leads her to conclude that context is important that context efects are variable, and She draws three conclusions. These and comprehender characteristics, non and environment in which language arises, and the comprehension process.

Dr Knoeferle explains: "Our immediate environment can affect language comprehension in real time. Such context effects vary by our characteristics as language users, how words relate to the environment and what comprehension process they contribute to." For example, she argues that comprehender characteristics such as age, literacy effects in language comprehension. Age particul nly afrects how quickly individuals
Considering comprehension processes, when either distinct or similar language cues or prompts contribute to the same comprehension process, Dr Knoeferle argues they affect comprehension in a similar manner: "Imagine you hear language about a musician and ats unclear such a he is acting or acted upon. Such ambiguity could be also showing who is acting." However if the comprehension processes to which marking in language versus context depictions contribute are distinct the

\section{CONCLUSION}

Dr Knoeferle's study aimed "to derive a more principled account of context effects in language comprehension and her scholarly review of 40 years of psycholinguistics research and the concepts it has produced more than fulfils her brief. Providing ample evidence that language does not Dr Knoferle equ (social) context, in language comprehension, but concern the link between context effects and language skills modulate context take place in a vacuum and cannot be

\section{คิ Behind the Research}

\section{Dr Pia Knoeferle}

E: admin-psycholinguistik@hu-berlin.de

W: http://amor.cms.hu-berlin.de/ knoeferp/index.html

\section{Research Objectives}

Prof Knoeferle argues that context influences language processing. Variation comes from how context is related to language and who we are as language users.

\section{Detail}

Pia Knoeferle

umboldt-Universität zu Berlin

Unter den Linden 6

Dermany

Bio

Pia Knoeferle obtained her PhD in 2005 from Saarland University, Germany In 2009, she joined Bielefeld University, and received tenure in 2015. Since 2015 she is full professor at the Humboldt-Universität zu Berlin. She action-edits for several journals and has founded an "Embodied and situated language processing" workshop (http://embodiedlanguage.org).

Funding

Coved support from funding by the German Research Counci.

Collaborators

- Ernesto Guerra

Camilo Rodriguez-Ronderos
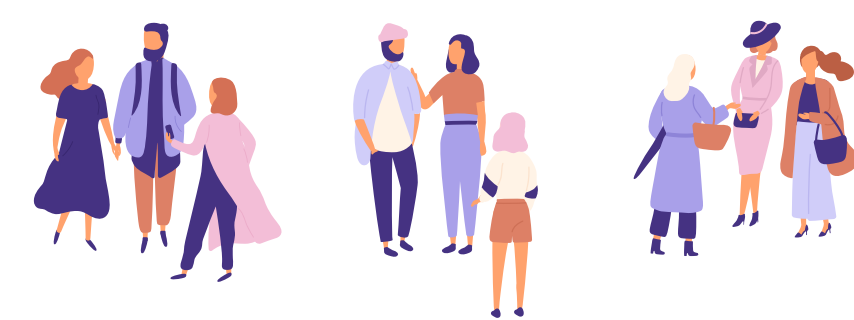

$\int_{1}^{1} 1$

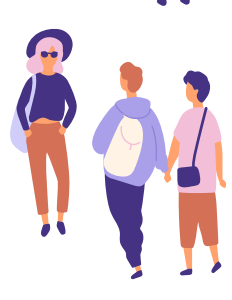

\section{References}

Knoeferle, P. (2019). Predicting (variability of) context effects in language. The Journal of Cultural Cognitive Science, 3, 141-158.

Knoeferle, P. and Guerra, E. (2016). Visually situated sion. Language and Linguistics Compass, 10(2), 66-82.

Knoeferle, P., Boukje, H., Crocker, M., and Münte, T. (2008). Visual scenes trigger immediate syntactic reanalysis: evidence from ERPs during situated spoken conversation. Cerebral Cortex, 18, 789-795.

Rodriquez Ronderos, C, Münster, K, Guerra, E, Kreysa, H., Rodríguez, A., Kröger, J., Kluth, T., Burigo, M. Abashidze, D., Nunnemann, E., and Pia Knoeferle, P. (2018). Eye tracking during visually situated language comprehension. flexibility and limitations in uncovering visual context effects. Journal of Visualized Experiments.

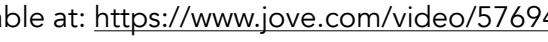

\section{Personal Response}

The use of eye-tracking and the event-related brain you working with to exploit the findings from these studies using other techniques?

My current research focus is not so much on the ing the role of context for a diverse range of language variety. Among that is language with figurative meaning, time, as well as language that is contextulised in an informal or a formal situation. I have in the past worked modelling to more formally simulate contextually situated language processing. 